\title{
Direct Evidence of Oxygen Vacancies in the First Sillén-BiMEVOX Intergrowth
}

\author{
D. Ávila Brande, ${ }^{*}$ A. R. Landa-Cánovas, ${ }^{* *}$ and L. C. Otero-Díaz**** \\ *Dpto. Química Inorgánica, Fac. CC. Químicas, Universidad Complutense, E-28040, Madrid, \\ SPAIN \\ ** Inst. Ciencia de Materiales de Madrid, CSIC, E-28049, Madrid, SPAIN \\ *** Centro de Microscopía, Universidad Complutense, E-28040, Madrid, SPAIN
}

High Resolution Electron Microscopy is a very useful tool for structure determination. However due to the aberrations in the electromagnetic lens system, the structural information contained in the images is not always a straightforward problem to broach. The information that can be obtained by qualitative HREM is therefore limited by Scherzer point-resolution, but for a coherent electron source (Field Emission Gun) the information of the microscope reaches beyond this point resolution. Moreover, due to the weak scattering power of light elements like oxygen they are not visible in conventional HREM images and only coordinates from heavy atoms can be obtained. In this sense Exit Wave Reconstruction using focal series [1] presents the great advantage that the amplitude as well as the phase from the exit wave (i.e. the electron wave leaving the specimen) are recovered. Since the light atoms are revealed in the phase of the exit wave [2] we can built up ideal structural model in new materials.

In this work, we have applied the exit wave reconstruction to determine the structural model of the first Sillén-BIMEVOX intergrowth with nominal composition $\mathrm{Bi}_{4} \mathrm{Cu}_{1 / 3} \mathrm{~W}_{2 / 3} \mathrm{O}_{7.8} \mathrm{Cl}$ [3] .

HREM was performed using a JEOL 3000F TEM yielding an information limit of $0.11 \mathrm{~nm}$. The exit wave was reconstructed from the focal series of twenty images at different defocus values $(\Delta \mathrm{f}=-15$ to $-20.7 \mathrm{~nm}$ ) using the IWFR software [4].

The synthesis conditions of the sample with nominal composition $\mathrm{Bi}_{4} \mathrm{~W}_{2 / 3} \mathrm{Cu}_{1 / 3} \mathrm{O}_{7.8} \mathrm{Cl}$, from the binary oxides $\mathrm{Bi}_{2} \mathrm{O}_{3}, \mathrm{WO}_{3}, \mathrm{CuO}$ and the oxyhalide $(\mathrm{BiOCl})$ (see ref. [3]) yields a new family of phases, which can be described as an ordered intergrowth of one Sillén block $\left[\mathrm{Bi}_{2} \mathrm{O}_{2} \mathrm{Cl}\right]$ and $n$ oxygen deficient blocks $\left[\mathrm{Bi}_{2} \mathrm{Cu}_{1 /(2 \mathrm{n}+1)} \mathrm{W}_{2 \mathrm{n} /(2 \mathrm{n}+1)} \mathrm{O}_{6-\delta}\right]_{\mathrm{n}}$ with $\mathrm{n}=1-4$ and $\delta=0.1$ (see Table I). From conventional TEM techniques, the lattice parameters and space group (P4/mmm) of the members $n$ $=1$ and 2 have been determined. After exit wave reconstruction, we have employed the phase of the exit wave that is proportional to the projected electrostatic potential of the structure to measure the coordinates for these two members taking into account the space group P4/mmm (Fig 1). Besides, the line intensity profile along the oxygen atoms located in the apical site $\mathrm{O}(1)$ and the equatorial one $\mathrm{O}(2)$ in the octahedra, performed on the enlargement of the Aurivillius block from the phase image, suggest that the oxygen vacancies should be statistically concentrated in the apical site $O(1)$ (Fig.2).

\section{References}

[1] W.M.J. Coene et al., Ultramicroscopy 64 (1996) 109.

[2] D. Van Dyck et al., Ultramicroscopy 64 (1996) 1.

[3] D. Ávila-Brande, Ph.D. Thesis. Universidad Complutense, 2006.

[4] Ishizuka K., IWFR software for EWR (Version 1.0, February 2005, HREM Research Inc.). 
$\left[\mathrm{Bi}_{2} \mathrm{O}_{2} \mathrm{Cl}\right]\left[\mathrm{Bi}_{2} \mathrm{Cu}_{1 / 3} \mathbf{W}_{2 / 3} \mathrm{O}_{6-\delta}\right]$

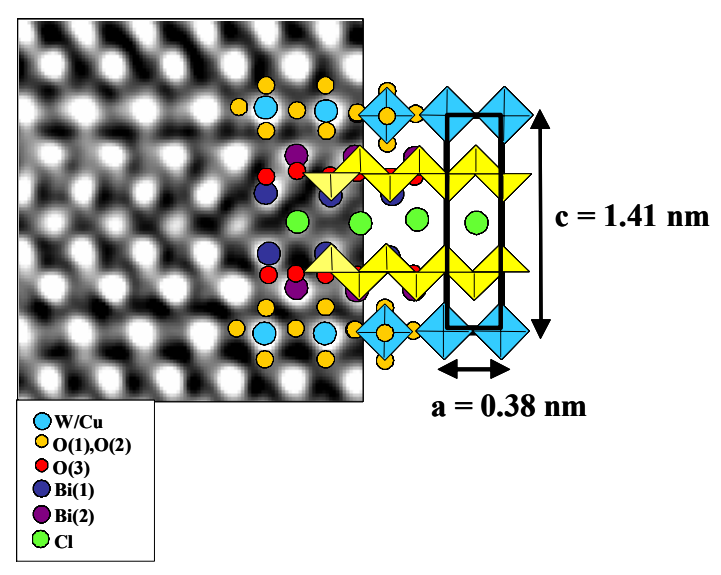

$\left[\mathrm{Bi}_{2} \mathrm{O}_{2} \mathrm{Cl}\right]\left[\mathrm{Bi}_{2} \mathrm{Cu}_{1 / 5} \mathrm{~W}_{4 / 5} \mathrm{O}_{6-\delta}\right]_{2}$

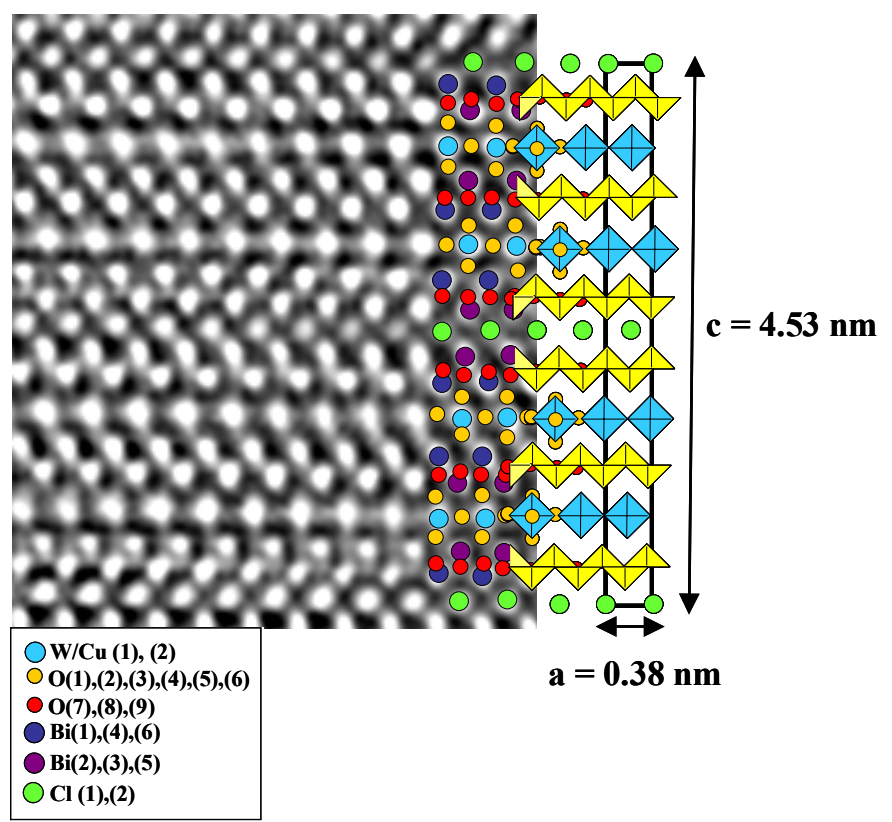

Fig. 1 Ideal structural models in the space group $\mathrm{P} 4 / \mathrm{mmm}$ built up by direct measurement of the coordiantes in the phase images.

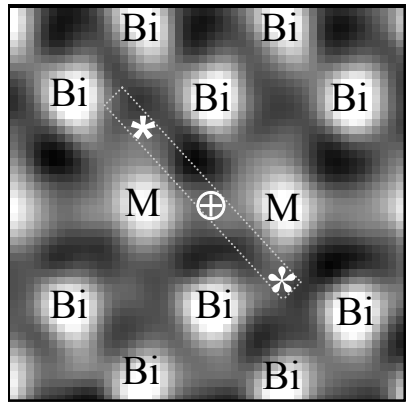

$\mathrm{M}: \mathrm{W} / \mathrm{Cu}$

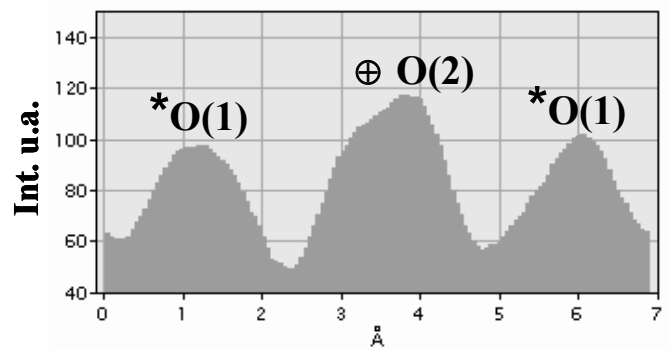

Fig. 2. Enlargement of the Aurivillius block $\left[\mathrm{Bi}_{2} \mathrm{~W} / \mathrm{CuO}_{6-\delta}\right]_{2}$. The lower intensity of the apical oxygens $\mathrm{O}(1)$ in relation to the equatorial ones, from the line profile measured in the outlined area, suggest that the vacancies are concentrated in the apical site.

TABLE 1. Members of a new family of Sillén-BIMEVOX intergrowth structures determined from HREM.

\begin{tabular}{|c|c|c|c|c|}
\hline $\mathbf{n}$ & Formula & W:Cu ratio & a axis (nm) & c axis (nm) \\
\hline 1 & $\left(\mathrm{Bi}_{2} \mathrm{O}_{2} \mathrm{Cl}\right)\left(\mathrm{Bi}_{2} \mathrm{Cu}_{1 / 3} \mathrm{~W}_{2 / 3} \mathrm{O}_{6-\delta}\right)$ & $2: 1$ & 0.38 & 1.41 \\
\hline 2 & $\left(\mathrm{Bi}_{2} \mathrm{O}_{2} \mathrm{Cl}\right)\left(\mathrm{Bi}_{2} \mathrm{Cu}_{1 / 5} \mathrm{~W}_{4 / 5} \mathrm{O}_{6-\delta}\right)_{2}$ & $4: 1$ & 0.38 & 4.53 \\
\hline 3 & $\left(\mathrm{Bi}_{2} \mathrm{O}_{2} \mathrm{Cl}\right)\left(\mathrm{Bi}_{2} \mathrm{Cu}_{1 / 7} \mathrm{~W}_{6 / 7} \mathrm{O}_{6-\delta}\right)_{3}$ & $6: 1$ & 0.38 & 3.12 \\
\hline 4 & $\left(\mathrm{Bi}_{2} \mathrm{O}_{2} \mathrm{Cl}\right)\left(\mathrm{Bi}_{2} \mathrm{Cu}_{1 / 9} \mathrm{~W}_{8 / 9} \mathrm{O}_{6-\delta}\right)_{4}$ & $8: 1$ & 0.38 & 7.80 \\
\hline $\mathrm{n}$ & $\left(\mathrm{Bi}_{2} \mathrm{O}_{2} \mathrm{Cl}\right)\left(\mathrm{Bi}_{2} \mathrm{Cu}_{1 /(2 \mathrm{n}+1)} \mathrm{W}_{2 \mathrm{n} /(2 \mathrm{n}+1)} \mathrm{O}_{6-\delta}\right)_{\mathrm{n}}$ & $2 \mathrm{n}: 1$ & 0.38 & - \\
\hline
\end{tabular}

